\title{
Combined ESWT \& RSW Therapy for Achilles Tendinopathy: A Prospective Study
}

\author{
A. Saxena, L. Shou, S. Ashraf \\ ${ }^{1}$ Department of Sports Medicine, Palo Alto Medical Foundation-Sutter, Palo Alto, CA \\ $23^{\text {nd }}$ Yr student, Samuel Merritt, CSPM
}

\author{
CORRESPONDING AUTHOR: \\ Amol Saxena \\ Department of Sports Medicine \\ Palo Alto Medical \\ Foundation-Sutter \\ Palo Alto, CA \\ E-mail: heysax@aol.com
}

DOI:

10.32098/mltj.04.2019.10

LEVEL OF EVIDENCE: 3

\begin{abstract}
SUMMARY
Introduction. Achilles tendinopathy is one of the most common overuse injuries of the foot and ankle in the active population. Many studies have shown radial sound wave therapy (RSW) or extra-corporeal shockwave therapy (ESWT) to be a safe and effective conservative treatment options when used independently.

Methods. In this prospective study, we examined the outcomes of treatment on Achilles tendinopathy combining these two modalities. We hypothesize improved results with the combination therapy and compare this with previous studies. The current study observes a cohort of 24 patients, who received the both treatments with mean age of $47.2 \pm 12.8$ years at the time of study. Each patient received three treatments initially and then subsequent treatments at 6 and/or 12 week follow up. Results. Pre-treatment VAS score was $6.3 \pm 1.3$ and RM score was 3.5 \pm 0.5 . Ultimately, these were reduced to $1.2 \pm 1.6(\mathrm{P}=0.00001)$ and $1.6 \pm 0.9(\mathrm{P}=0.00001)$ respectively at $17 \pm 4.5$ month follow-up. Patients with paratendinosis had better outcomes than insertional Achilles pathology.

Conclusions. Our results show a significant improvement in outcome measures in patients treated with ESWT and RSW, as compared to other studies. We conclude that the dual treatment method is a safe and improved method of treatment for Achilles tendinopathy compared to isolated use of ESWT or RSW.
\end{abstract}

\section{KEY WORDS}

Achilles; radial soundwave; extra-corporeal; shockwave

\section{INTRODUCTION}

Achilles tendinopathy has been reported as the most common overuse injury in sports medicine clinics (1). Standard conservative treatments include eccentric loading, stretching, heel lifts, avoidance of painful activities, and non-steroidal anti-inflammatory drugs. Several studies have demonstrated that eccentric training can be effective for insertional and non-insertional Achilles tendinopathy (2-6). However, conservative management is inadequate in many patients with Achilles tendinopathy. Damage to the Achilles tendon usually results from chronic overuse. It is the result of accumulative impact loading and repetitive microtrauma to the tendon (1). Interestingly, inflammatory changes are present, however, inflammatory mediators are absent, making the term Achilles tendinitis a misnomer (7). Tendinopathy is more of a generic term used to encompass intrinsic and/or extrinsic damage to the tendon or paratenon from the watershed region ("mainbody" or mid-portion) to its insertion. From an anatomic standpoint, tendinopa- thy describes fraying of the tendon due to a failed healing response of the extracellular matrix $(8,9)$.

The treatment of tendinopathies with radial soundwave (RSW) and extra-corporeal shockwave (ESWT), collectively termed soundwave (SW) has emerged as an alternative option if non-surgical treatment fails prior to surgical interventions. Foot pathologies such as Achilles tendinopathy or plantar fasciitis are widely established to have shock wave indications. Basic science studies show that SW increases blood flow to the treatment site and induce an inflammatory-mediated healing process. Local anesthesia may alter the inflammatory response and angiogenesis of which SW promotes and is therefore contra-indicated (10). The methodology of SW administration for patients with Achilles tendinopathy has varied significantly in previous studies, making it difficult to determine its effectiveness. In fact, most high-level studies only involved RSW and not ESWT. The purpose of the current study is to prospectively evaluate combined ESWT and RSW treatment for Achilles tendinopathy. The results will be compared to other prior studies. 


\section{METHODS}

35 Patients with Achilles tendinopathy average age $48.7 \pm 13.4$ years, were treated from June 2016 through July 2017 with both focused ESWT (Storz Duolith, Storz Medical AG, Tägerwilen, $\mathrm{CH}$ ) and radial soundwave (Orthopulse, Storz Medical AG, Tägerwilen, CH). IRB approval was obtained. The symptomatic region was treated with ESWT at $0.15 \mathrm{~mJ} / \mathrm{mm}^{2}, 6 \mathrm{~Hz}$ and with RSW $2.4 \mathrm{Bar}, 13$ $\mathrm{Hz}$, both for 2500 pulses, three times at weekly intervals. If patients' VAS score was "4" or more at 12 weeks, an additional treatment was rendered. Patients were advised to avoidance excessive stretching and eccentrics beyond neutral (11). They were advised to use heel cushions if they felt better with heel elevation. They were required to avoid both NSAIDs and an increase of activity level during the three-week treatment period.

Inclusion criteria were the ability to document Pre- \& post-treatment VAS and $\mathrm{R} \& \mathrm{M}$ scores at appropriate intervals, (three months post-treatment and at follow-up, which was generally one year or more post-treatment). Diagnosis of Achilles tendinopathy (insertional, paratendinosis and tendinosis) was confirmed by an experienced clinician. Scores were confirmed by a Fellow and entered into the patients' medical records for subsequent review. A different Fellow performed a follow-up phone call and email at a year or later. Exclusion criteria were the inability to have VAS and scores available. Patients were also excluded if they were unable to complete the treatment recommendations of avoidance of NSAIDs, aggressive stretching, dramatic change in activity level. The "dropouts" who underwent surgery by the senior author were also assessed.

\section{RESULTS}

35 patients received treatment on 38 Achilles tendons during the study period. There were 23 males and 12 females. Pre-treatment VAS score was $6.3 \pm 1.3$ and RM $3.5 \pm 0.5$. The average number of treatments for the entire cohort was 3.6 \pm 0.6 . 12-week VAS score was reduced to $3.1 \pm 1.8(\mathrm{P}=.00001)$. $\mathrm{RM}$ score improved at 12 weeks to $2.4 \pm 1.1(\mathrm{P}=.00001)$. During this timeframe, seven patients treated with the combined therapy elected to undergo surgery. Seven additional patients were unresponsive to the Fellow's contact attempts.

The 24 patients ( 20 males and 11 females) who had followup at an average of $17 \pm 4.5$ months post-treatment, had an average age of $47.2 \pm 12.8$ years. The VAS score further reduced in this cohort of 24 patients to $1.2 \pm 1.6(\mathrm{P}=.00001)$ and the RM score as well, 1.6 $\pm 0.9(\mathrm{P}=.00001)$. In this cohort, twelve patients had a VAS of "0" and 14 had a RM of " 1 ". Therefore at least $50 \%$ had complete pain relief and full return to activity.

There was no difference in scores during any time period of the study between males and females. Patients with paratendinosis had significantly better 12 month or more months scores than those with insertional pathology. There were no other significant differences as to the anatomic location of patients' tendinopathy and outcome measures.

The subset of six patients who underwent surgery by the same clinician had an average of $3.5 \pm 0.8$ treatments. Their average age was $51.7 \pm 13.0$ years. Their post-operative VAS and RM scores significantly improved as well at their current post-operative status recorded at an average $16.5 \pm 5.9$ months, $\mathrm{P}=.008$ and .006 , respectively. The surgical patients' 12 week post-soundwave treatment VAS and RM scores had not significantly improved from baseline, $P=.20$ and .36 , respectively. One of these patients with fibromyalgia is currently six months post-surgery with a VAS score of 4, is able to bicycle 30 minutes and is currently receiving additional ESWT treatments. The other five surgical patients had three with a " 0 " and two with a " 1 " with their VAS and four had " 1 " with the RM, post-operatively.

\section{DISCUSSION}

The current study showed excellent effectiveness of combining focused ESWT and RSW. The fact that over $50 \%$ of the cohort followed over 17 months had zero pain on the VAS and full activity on the RM score for a typically chronic condition is very encouraging. Most studies on SW don't go beyond 3-12 months of assessment. Our study's main weakness is that there was no control or placebo group. This is typical of unfunded studies.

Comparing the effectiveness of other studies can be difficult as there are variable protocols, end points and technologies. In fact, most prior studies only involved RSW. For plantar fasciitis, ESWT has shown to be more effective than RSW (12). We reviewed several studies on SW for Achilles tendinopathy (table I A-D); seven previous studies $(13,14,15$, $16,17,18,19)$ showed significant improvement in patients with Achilles tendinopathy treated with RSW. Five of those seven studies $(13,14,15,16,19)$ had control groups that did not receive shockwave treatment. The shockwave intervention group had significant improvement compared to the control group in all five of these studies, three of which had a level of clinical evidence of " 1 " $(14,15,16)$.

Two of the nine previous studies $(20,21)$ analyzed in table I A-D failed to show significant improvements in the shockwave intervention group versus control groups that did not receive shockwave. Both of these studies had a level of clinical evidence " 1 ". The first of these two studies, Costa et 
Table I A. Shockwave Treatment for Achilles Tendinopathy.

\begin{tabular}{|c|c|c|c|c|c|c|c|c|}
\hline $\begin{array}{l}\text { Author of } \\
\text { Study }\end{array}$ & $\begin{array}{l}\text { Level of } \\
\text { Clinical } \\
\text { Significance }\end{array}$ & $\begin{array}{l}\text { \# of } \\
\text { Patients }\end{array}$ & $\begin{array}{l}\text { Average Age of } \\
\text { Patients (years) } \\
\text { [C=Control, } \\
\text { I=Shockwave } \\
\text { Intervention] }\end{array}$ & $\begin{array}{l}\text { Type of } \\
\text { Shockwave } \\
\text { Used } \\
\text { [FSWT = } \\
\text { Focused Shock } \\
\text { Wave, RSW = } \\
\text { Radial Shock } \\
\text { Wave] }\end{array}$ & $\begin{array}{l}\text { Shockwave } \\
\text { Device(s) }\end{array}$ & $\begin{array}{l}\text { Shockwave } \\
\text { \# of } \\
\text { Impulses per } \\
\text { treatment }\end{array}$ & $\begin{array}{l}\text { Shockwave } \\
\text { Frequency }\end{array}$ & $\begin{array}{l}\text { Significant } \\
\text { Improvement } \\
\text { with } \\
\text { Shockwave } \\
\text { Treatment? } \\
\text { (Detailed } \\
\text { Results in } \\
\text { table 1D) }\end{array}$ \\
\hline Costa 2005 & 1 & 49 & $\begin{array}{l}\mathrm{C}=47.7 \pm 13.5 \\
\mathrm{I}=58.7 \pm 10.8\end{array}$ & ESWT & $\begin{array}{l}\text { Storz Modulith } \\
\text { SLK }\end{array}$ & 1500 & $\begin{array}{l}\text { Not } \\
\text { Mentioned }\end{array}$ & No \\
\hline Furia 2006 & 3 & 68 & $\begin{array}{l}C=52.6 \pm 15.9 \\
I=50 \pm 9.2\end{array}$ & ESWT & $\begin{array}{l}\text { Dornier Epos } \\
\text { Lithotripter }\end{array}$ & 3000 & $1 \mathrm{~Hz}-4 \mathrm{~Hz}$ & Yes \\
\hline $\begin{array}{l}\text { Rasmussen } \\
2008\end{array}$ & 1 & 48 & $\begin{array}{l}C=46 \pm 13 \\
I=49 \pm 9\end{array}$ & RSW & Piezoson 100 & 2000 & $50 \mathrm{~Hz}$ & Yes \\
\hline Rompe 2008 & 1 & 50 & $\begin{array}{l}\mathrm{C}=39.2 \pm 10.7 \\
\mathrm{I}=40.4 \pm 11.3\end{array}$ & RSW & $\begin{array}{l}\text { EMS Swiss } \\
\text { Dolor-Clast }\end{array}$ & 2000 & $8 \mathrm{~Hz}$ & Yes \\
\hline Rompe 2009 & 1 & 68 & $\begin{array}{l}\mathrm{C}=46.2 \pm 10.2 \\
\mathrm{I}=53.1 \pm 9.6\end{array}$ & RSW & $\begin{array}{l}\text { EMS Swiss } \\
\text { Dolor-Clast }\end{array}$ & 2000 & $8 \mathrm{~Hz}$ & Yes \\
\hline Saxena 2011 & 2 & 60 & $\mathrm{I}=48.32 \pm 12.94$ & RSW & $\begin{array}{l}\text { Storz D-Actor } \\
200\end{array}$ & 2500 & $11-13 \mathrm{~Hz}$ & Yes \\
\hline Wu 2016 & $\begin{array}{c}3 \\
\text { (estimated) }\end{array}$ & 67 & $\begin{array}{l}\text { I (Non-Deformity) }=37.6 \\
\pm 9.2 \\
\text { I (with Haglund's } \\
\text { Deformity) }=35.8 \pm 7.4\end{array}$ & RSW & $\begin{array}{l}\text { EMS Swiss Dolor- } \\
\text { Clast }\end{array}$ & 2000 & $8 \mathrm{~Hz}$ & Yes \\
\hline $\begin{array}{l}\text { Gerdesmeyer } \\
2017\end{array}$ & 3 & 53 & $\begin{array}{l}\mathrm{C}=45.0 \pm 8.5 \\
\mathrm{I}=43.6 \pm 9.4\end{array}$ & $\begin{array}{l}\text { EMTT } \\
\text { (Electromagnetic } \\
\text { Transduction Therapy) }\end{array}$ & Cellactor MT1 & 3600 & $3 \mathrm{~Hz}$ & Yes \\
\hline $\begin{array}{l}\text { Vahdatpour } \\
2018\end{array}$ & 1 & 43 & $\begin{array}{l}C=54.3 \pm 12.4 \\
I=54.9 \pm 11.3\end{array}$ & $\begin{array}{l}\text { ESWT and } \\
\text { RSW }\end{array}$ & $\begin{array}{l}\text { "Standard } \\
\text { Electromagnetic } \\
\text { Shockwave } \\
\text { Device" }\end{array}$ & $\begin{array}{l}1500 \\
(\mathrm{ESWT}) \\
3000 \\
(\mathrm{RSW}) \\
\end{array}$ & $\begin{array}{l}2.3 \mathrm{~Hz} \\
(\mathrm{ESWT}) \\
2.21 \mathrm{~Hz} \\
(\mathrm{RSW})\end{array}$ & No \\
\hline $\begin{array}{l}\text { Current } \\
\text { Study }\end{array}$ & 3 & 38 & $I=48.7 \pm 13.4$ & $\begin{array}{l}\text { ESWT and } \\
\text { RSW }\end{array}$ & $\begin{array}{l}\text { Storz Duolith } \\
\text { (FSWT) } \\
\text { Orthopulse } \\
\text { (RSW) }\end{array}$ & $\begin{array}{l}2500 \\
\text { (ESWT) } \\
2500 \\
\text { (RSW) }\end{array}$ & $\begin{array}{l}6 \mathrm{~Hz} \\
(\mathrm{ESWT}) \\
13 \mathrm{~Hz} \text { (RSW) }\end{array}$ & Yes \\
\hline
\end{tabular}

al. (20) conducted a double-blind randomized placebo-controlled trial which concluded that there was no significant evidence for use of shockwave therapy for chronic Achilles tendon pain (three of their patients had pain at Achilles insertion while the remaining 46 pts were diagnosed with mid-portion Achilles tendinosis). However, we found multiple differences in the methodology of this study when comparing it to the other eight studies.

The first of the differences in methodology for the Costa et al. study (20) was the average age of the control vs. shockwave intervention group. The control group was $47.7 \pm 13.5$ years old while the shockwave intervention group was 58.7 \pm 10.8 years old (specifically stated in table $\mathbf{I}$ of Costa et al.). This age difference of an average of 11 years between groups may have affected healing rates. Another difference between this study and the others was the number of shockwave impulses per treatment. Costa et al. used 1500 impulses while every other study used a minimum of 2000 impulses. Additionally, shockwave treatments had monthly intervals, while seven of the other eight studies had treatment intervals of one week or less (the other, Furia et al., only gave patients one treatment of high-impulse ESWT). Costa et al was also the only study not to state the shockwave impulse frequency. Differences in shockwave number of impulses and frequency as well as time interval between treatments in comparison to other studies may have yielded less significant outcomes regarding improvement in the shockwave intervention group. Additionally, the study did not state specific instructions to patients regarding avoidance of painful activity and NSAID use.

The primary endpoint of Costa 2005 was VAS pain with walking. The baseline values for the shockwave interven- 
Table I B. Shockwave Treatment for Achilles Tendinopathy.

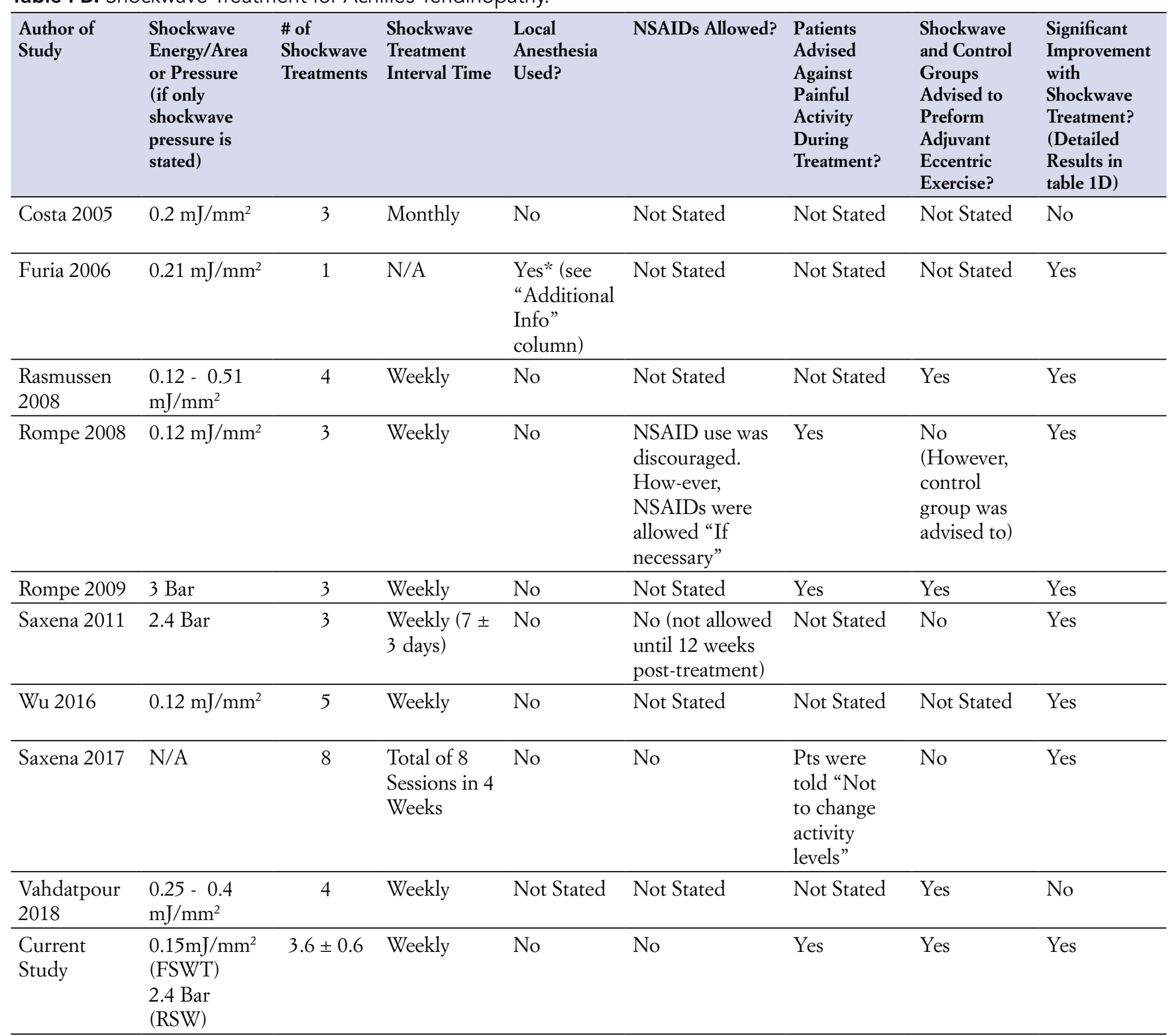

tion group and control group were matched. The results showed that the shockwave group improved 15.8 points (on a 100 point scale) more than the control group at one month post-treatment follow up. This difference was not considered significant. However, the author acknowledged "The possibility for Type 2 error (ie, the sample size was too small to detect a meaningful treatment effect)." Two of the secondary endpoints were VAS pain at rest and VAS pain with sporting activity. The VAS for pain at rest at one month post shockwave treatment follow up showed a difference of 7.8 in favor of the shockwave group, which was not considered signifi- cant. However, the average VAS for pain at rest at baseline in the shockwave group was 11.4 points higher compared to the control. Therefore, the improvement in the shockwave intervention group would have been an average of 19.2 better than that of the control group, which may have been considered a significant result if comparison of improvement was measured as opposed to simple endpoint difference. A similar, but less extreme issue was seen with VAS pain with sporting activity when baseline values were analyzed.

As previously mentioned, seven of the nine prior studies showed significant improvement in patients with Achilles 
Table I C. Shockwave Treatment for Achilles Tendinopathy.

\begin{tabular}{|c|c|c|c|c|c|c|}
\hline $\begin{array}{l}\text { Author of } \\
\text { Study }\end{array}$ & $\begin{array}{l}\text { Advised } \\
\text { Against } \\
\text { Excessive } \\
\text { Stretching? }\end{array}$ & $\begin{array}{l}\text { Follow-Up (for } \\
\text { Primary Endpoints) } \\
\text { [Time after } \\
\text { Completion } \\
\text { of Shockwave } \\
\text { Treatment(s)] }\end{array}$ & $\begin{array}{l}\text { Primary } \\
\text { Endpoint(s) }\end{array}$ & $\begin{array}{l}\text { Secondary } \\
\text { Endpoint(s) }\end{array}$ & Significant Side Effects & $\begin{array}{l}\text { Significant } \\
\text { Improvement } \\
\text { with Shockwave } \\
\text { Treatment? } \\
\text { (Detailed Results } \\
\text { in table I D) }\end{array}$ \\
\hline Costa 2005 & Not Stated & 1 month & $\begin{array}{l}\text { VAS score } \\
\text { for pain on } \\
\text { walking }\end{array}$ & $\begin{array}{l}\text { VAS pain at rest } \\
\text { and VAS with } \\
\text { sporting activity, } \\
\text { FIL, Eqol, ankle } \\
\text { ROM, calf } \\
\text { circumference, } \\
\text { Achilles tendon } \\
\text { diameter }\end{array}$ & $\begin{array}{l}2 \text { Achilles tendon } \\
\text { ruptures (see } \\
\text { "Additional } \\
\text { Information" } \\
\text { column) }\end{array}$ & No \\
\hline Furia 2006 & Not Stated & $\begin{array}{l}1 \text { month } \\
3 \text { months } \\
12 \text { months }\end{array}$ & $\begin{array}{l}\text { VAS and RM } \\
\text { Scores }\end{array}$ & $\mathrm{N} / \mathrm{A}$ & $\begin{array}{l}\text { None (one pt had } \\
\text { transient numbness } \\
\text { that resolved within } \\
24 \text { hours post- } \\
\text { treatment) }\end{array}$ & Yes \\
\hline $\begin{array}{l}\text { Rasmussen } \\
2008\end{array}$ & No & $\begin{array}{l}4 \text { weeks } \\
8 \text { weeks } \\
12 \text { weeks }\end{array}$ & AOFAS Score & VAS Score & None & Yes \\
\hline Rompe 2008 & Yes & 1 month & VISA-A & $\begin{array}{l}\text { General assessment } \\
\text { (using 6-point } \\
\text { Likert scale) and } \\
\text { pain assessment }\end{array}$ & None & Yes \\
\hline Rompe 2009 & Not Stated & 1 month & VISA-A & $\begin{array}{l}\text { General assessment } \\
\text { (using 6-point } \\
\text { Likert scale) and } \\
\text { Load-Induced Pain } \\
\text { (NRS) }\end{array}$ & None & Yes \\
\hline Saxena 2011 & $\begin{array}{l}\text { Not } \\
\text { Specifically } \\
\text { Stated ("Pts } \\
\text { were allowed } \\
\text { to stretch } \\
\text { gastrocs") } \\
\end{array}$ & $\begin{array}{l}12 \text { months or } \\
\text { more }\end{array}$ & RM Score & $\mathrm{N} / \mathrm{A}$ & None & Yes \\
\hline Wu 2016 & Not Stated & $\begin{array}{l}14.5(7.2) \\
\text { months for } \\
\text { Non-Deformity } \\
\text { Group, } \\
15.3(6.7) \text { months } \\
\text { for Haglund's } \\
\text { Deformity group }\end{array}$ & $\begin{array}{l}\text { VISA-A Score } \\
\text { and 6-Point } \\
\text { Likert Scale }\end{array}$ & $\mathrm{N} / \mathrm{A}$ & None & Yes \\
\hline $\begin{array}{l}\text { Gerdesmeyer } \\
2017\end{array}$ & Yes & 12 weeks & VAS Score & RM Score & None & Yes \\
\hline $\begin{array}{l}\text { Vahdatpour } \\
2018\end{array}$ & No & $\begin{array}{l}\text { Immediately post } \\
\text { treatment } \\
4 \text { weeks } \\
16 \text { weeks } \\
\end{array}$ & $\begin{array}{l}\text { VAS Score and } \\
\text { AOFAS }\end{array}$ & $\mathrm{N} / \mathrm{A}$ & None & No \\
\hline $\begin{array}{l}\text { Current } \\
\text { Study }\end{array}$ & Yes & $\begin{array}{l}12 \text { weeks } \\
12+\text { months }\end{array}$ & $\begin{array}{l}\text { VAS and RM } \\
\text { Scores }\end{array}$ & $\mathrm{N} / \mathrm{A}$ & None & Yes \\
\hline
\end{tabular}


tendinopathy treated with shockwave therapy. Furia et al (13) was a unique study in a multiple ways. Instead of having multiple shockwave treatments (like all other eight studies), this study only gave patients one treatment of high-impulse focused shockwave therapy (ESWT), with 3000 impulses (the highest for ESWT among the three studies in $1 \mathrm{~A}-\mathrm{D}$ that used ESWT). This appears to be an effective method of application of ESWT on Achilles tendinopathy, as the mean VAS and RM scores for the shockwave treatment group were significantly improved at one, three, and 12 months after treatment compared to the control group.

Another unique characteristic of the Furia et al study is that, of the 35 patients in the shockwave group, 12 patients had local anesthetic (LA) and the other 23 had non-local anesthetic (NLA). The non-local anesthesia was described by the author as an "Anesthesia other than local." Results showed that improvement in VAS scores for the LA subgroup was significantly less than improvement in the NLA subgroup. This indicates that anesthetic decreases the effectiveness of shockwave treatment. However, the sample size used with the two subgroups was too small for statistical analyses.

Furia et al also had a small subset of the intervention group (three patients) in a brief immobilization boot (three-tosix days). This group had an even better outcome than the shockwave-non-immobilized group. Although this sample size was too small for any significant analysis, it is potentially useful information in directing a future study of to compare the effectiveness of shockwave treatment with brief immobilization following treatment to shockwave treatment without any period of immobilization. It could be these patients had partial tears/avulsions. A weakness of the Furia et al study was that it did not state instructions for patients during the treatment period such as NSAID use, advising against painful activity, etc.

Rasmussen et al (14) conducted a level-1 evidence study using RSW. This study compared improvements in a control group, which received standard conservative treatment for Achilles tendinopathy consisting of eccentric training and stretching exercises, to a shockwave intervention group that also received the same conservative treatment. The results showed that the primary endpoint, AOFAS score, increased more over time in the shockwave intervention group than in the control group. AOFAS scores were recorded at baseline, four weeks post-treatment completion, eight weeks post-treatment completion, and 12 weeks post-treatment completion. Improvements at eight and 12-week follow-up were significantly greater in shockwave intervention group than control. Although AOFAS scores were improved at four-week follow up more in the shockwave group than the control, these results at this time were not significant. This provides another explanation for why results in Costa et al may not have been significant, as they only measured their primary endpoint at one-month post-treatment completion. The only unique characteristic regarding Rasmussen et al compared to the other 8 previous studies was that they used a much higher shockwave frequency, $50 \mathrm{~Hz}$. It is unclear if this had any effect on the outcome.

Two level-1 clinical evidence studies were conducted by Rompe et al in 2008 (15) and 2009 (16). The 2008 study examined the effectiveness of extracorporeal shockwave therapy versus eccentric loading in patients with chronic insertional Achilles tendinopathy. The study compared a control group that received eccentric training, which is a standard conservative care treatment for Achilles tendinopathy, to a shockwave intervention group (all patients in both groups had been diagnosed with chronic insertional Achilles tendinopathy). The shockwave group was discouraged from any adjuvant treatment, such as eccentric exercise, excessive stretching, etc. Shockwave group patients were allowed to take NSAIDs if necessary, however this was discouraged. Patients in both groups were advised against painful activity. RSW was administered in three treatments at weekly intervals without local anesthetic. Primary endpoint was VISA-A scores at follow up one month post-treatment completion. For all outcome measures, the shockwave therapy group showed significantly more favorable results than the group treated with eccentric loading alone.

Rompe et al 2009 examined the effectiveness of extracorporeal shockwave therapy plus eccentric loading versus eccentric loading alone in patients with chronic non-insertional ("Mid-portion") Achilles tendinopathy. Aside from the differences in assignment of eccentric exercise amongst the groups, the methodology was very similar to that of Rompe et al's 2008 study. The results showed that the shockwave plus eccentric loading had significantly better outcomes on VISA-A, Likert scale, and NRS when compared to the group treated with eccentric loading alone at 1 month post-shockwave treatment completion.

Saxena et al. 2011 (17) conducted a cohort study using RSW ("EPAT") as an isolated treatment for Achilles tendinopathy. Although there was no control group, the patients had all been diagnosed with chronic Achilles tendinopathy, meaning they had the condition for at least three months, and usually six-plus months and did not improve with conservative treatment during that time period. Patients in this study received RSW with 2500 impulses per treatment for three treatments at weekly intervals without local anesthetic, making the treatment administration similar to Rompe et al 2008 and Rompe et al 2009. NSAIDs were not allowed until a minimum of 12 weeks post-treatment completion. The primary endpoint was RM score at $12+$ months post-treatment completion, which were compared to patients' RM 
Table I D. Shockwave Treatment for Achilles Tendinopathy.

\begin{tabular}{|c|c|c|}
\hline Author of Study & Additional Information & Results \\
\hline Costa 2005 & $\begin{array}{l}\text { For the } 2 \text { Achilles ruptures in the } \\
\text { shockwave treatment group, it appears } \\
\text { as though no instructions were given } \\
\text { to pts regarding avoidance of painful } \\
\text { activity, avoidance of excess stretching, } \\
\text { etc. Also, pts in shockwave treatment } \\
\text { group averaged } 11 \text { years older than } \\
\text { control group. These } 2 \text { pts were } 65 \text { and } \\
62 \text { y/o. Ruptures occurred within the } \\
\text { first } 2 \text { weeks of treatment in both pts. }\end{array}$ & $\begin{array}{l}\text { Neither the VAS scores for pain at rest or during sport participation } \\
\text { showed a significant difference between groups. }\end{array}$ \\
\hline Furia 2006 & $\begin{array}{l}\text { Of the } 35 \text { pts in the shockwave group, } \\
12 \text { pts had local anesthetic (LA) and } \\
\text { the other } 23 \text { had non-local anesthetic } \\
\text { (NLA). }\end{array}$ & $\begin{array}{l}\text { The mean VAS and RM scores for the shockwave treatment group were } \\
\text { significantly improved at } 1,3 \text {, and } 12 \text { months after treatment compared } \\
\text { to control group. } \\
\text { In addition, improvement in VAS scores for LA sub-group was } \\
\text { significantly less than improvement in the NLA sub-group. This indicates } \\
\text { that local anesthetic decreases the effectiveness of shockwave treatment. }\end{array}$ \\
\hline Rasmussen 2008 & $\begin{array}{l}\text { AOFAS scores improved at } 4 \text { week } \\
\text { follow-up, but were not significant. } \\
\text { Improvements at } 8 \text { and } 12 \text { week follow- } \\
\text { ups were significant ( } \mathrm{p}=0.01 \text { at } 8 \text { wks } \\
\text { and } p=0.04 \text { at } 12 \mathrm{wks} \text { ) }\end{array}$ & $\begin{array}{l}\text { AOFAS score after treatment increased more over time in the } \\
\text { shockwave-intervention group than in the control group }(p=0.05)\end{array}$ \\
\hline Rompe 2008 & --- & $\begin{array}{l}\text { For all outcome measures, the shockwave therapy group showed } \\
\text { significantly more favorable results than the group treated with eccentric } \\
\text { loading alone. }\end{array}$ \\
\hline Rompe 2009 & $\cdots$ & $\begin{array}{l}\text { Shockwave plus eccentric loading had significantly better outcomes on } \\
\text { VISA-A, Likert scale, and NRS at } 1 \text { month post-shockwave-treatment } \\
\text { completion than eccentric loading alone }\end{array}$ \\
\hline Saxena 2011 & --- & $\begin{array}{l}\text { Pts receiving shockwave therapy showed a significant improvement in } \\
\text { RM scores }\end{array}$ \\
\hline Wu 2016 & $\begin{array}{l}\text { There was no control group that } \\
\text { was not treated with shockwave. } \\
\text { Rather, there were two intervention } \\
\text { groups, one with Haglund's deformity } \\
\text { accompanying Achilles tendinopathy } \\
\text { and another without the deformity } \\
\text { accompanying Achilles tendinopathy. }\end{array}$ & $\begin{array}{l}\text { Outcomes with regard to VISA-A score and 6-point Likert scale } \\
\text { achieved significant improvements in both the deformity (Haglund's) } \\
\text { and non-deformity groups compared to baseline. However, there } \\
\text { was a significantly greater improvement in VISA-A scores for the } \\
\text { non-deformity group compared to the deformity group. }\end{array}$ \\
\hline $\begin{array}{l}\text { Gerdesmeyer } \\
2017\end{array}$ & $\begin{array}{l}\text { All pts (both in control and EMTT } \\
\text { Shockwave groups) were instructed to } \\
\text { use heel-pads with } 1 \mathrm{~cm} \text { heel cushion. }\end{array}$ & $\begin{array}{l}\text { Both the control group (heel-cushion only treatment) and the } \\
\text { shockwave-intervention group (EMTT shockwave plus heel- } \\
\text { cushion) had significant improvements in both VAS and RM scores. } \\
\text { The difference between the groups was significantly in favor of the } \\
\text { shockwave-intervention group for VAS. RM scores were also improved } \\
\text { more in the shockwave intervention group compared to control, but this } \\
\text { was not statistically significant. }\end{array}$ \\
\hline $\begin{array}{l}\text { Vahdatpour } \\
2018\end{array}$ & $\cdots$ & $\begin{array}{l}\text { Author: "Our findings indicated that ESWT has improving effects both } \\
\text { on pain and AOFAS score of patients, but due to small sample size, the } \\
\text { results were not statistically significant." }\end{array}$ \\
\hline Current Study & --- & $\begin{array}{l}\text { There was a significant improvement in VAS and RM scores in patients } \\
\text { treated with combined FSWT and RSW. }\end{array}$ \\
\hline
\end{tabular}


scores at baseline. The results showed that patients receiving shockwave therapy had a significant improvement in RM scores. Both males and females had an average baseline RM score of 3.3. However, after shockwave intervention, males improved to an average RM of 1.55 while females improved to an average of 1.83 . This was not considered statistically significant, given the sample size. Interestingly, in Vahdatpour et al's 2018 study, 35 of the subjects were female compared to only 8 males. We did not see any significant differences in our current study as well. It is advisable that future studies analyze the outcome measures of ESWT on males versus females. This could potentially lead to a better understanding of hormonal influence on the healing response induced by ESWT.

Wu et al. (18) compared the effectiveness of extracorporeal shockwave therapy in a group diagnosed with insertional Achilles tendinopathy accompanied by Haglund's deformity versus another group diagnosed with insertional Achilles tendinopathy without the deformity. Haglund's deformity is defined as complex of symptoms involving a superolateral calcaneal prominence, retrocalcaneal bursitis, and superficial adventitious bursitis (18). Sundararajan and Wilde 2014 conducted a study exhibiting that Haglund's deformity was present in $25 \%$ of patients with insertional Achilles tendinopathy (18). There was no control group. RSW was administered during five treatments of 2000 impulses each with weekly intervals and without local anesthetic. This method of treatment was similar to that of the shockwave intervention groups in both studies by Rompe et al and Saxena et al 2011, but with two additional RSW treatments. The primary endpoints were VISA-A score and 6-point Likert scale. Both primary endpoint measures achieved significant improvements in both the deformity (Haglund's) and non-deformity groups compared to baseline. However, there was a significantly greater improvement in VISA-A scores for the non-deformity group compared to the deformity group. A disadvantage of this study was that adjuvant treatment such as eccentric exercise, NSAIDs, and avoidance of painful activity were not stated.

Gerdesmeyer et al 2017 (19) conducted a study using Electromagnetic Transduction Therapy (EMTT, Cellactor $1^{\circledR}$, Storz Medical AG, Tägerwilen, CH), which has a very similar mechanistic theory to that of ESWT (8). This study compared improvement in VAS and RM scores from baseline in two groups of patients with Achilles tendinopathy; the control group received $1-\mathrm{cm}$ heel-cushions as their only treatment while the intervention group received EMTT plus $1-\mathrm{cm}$ heel-cushion. Patients were instructed not to change their activity levels during the treatment period. The EMTT plus heel-cushion group received eight EMTT treatments during a four week period. Both the control group (heel-cushion only) and the EMTT plus heel cushion group had significant improvements in both VAS and RM scores. The difference between the groups was significantly in favor of the EMTT plus heel-cushion for VAS scores. RM scores were also improved more in the EMTT plus heel-cushion group compared to control, but this was not statistically significant.

Vahdatpour et al (21) conducted a double-blind placebo-controlled clinical trial that used focused shockwaves and radial shockwaves concurrently in the intervention group. The study concluded that, although there was an improvement in pain and AOFAS scores of patients, the results were not significant (although there was a significant improvement in AOFAS scores in ESWT group at 16 wks post-intervention). The author concluded that the lack of statistical significance was due to the small sample size of the study. In addition, $100 \mathrm{mg}$ diclofenac sodium was administered daily for two weeks simultaneous with shockwave intervention. One of the theories behind shockwave use for chronic tendinopathies is that it stimulates a new healing response similar to that in the initial acute phase. Therefore, NSAID administration may have diminished the effects of shockwave treatment for tendinopathies in this study.

The only significant side effects found in the nine previous studies reviewed listed in tables I A-D were two Achilles ruptures, both occurring in the shockwave treatment group in the Costa et al study. However, it appears as though no instructions were given to patients regarding avoidance of painful activity. Also, patients in ESWT treatment group averaged 11 years older than the control group. The two patients with Achilles ruptures were 62 and

65 years old and both ruptures occurred within the first two weeks of treatment.

A total 10 studies on the use of shockwave therapy for Achilles tendinopathy were analyzed in table I A-D. Eight of these studies showed significant improvement in patients with Achilles tendinopathy treated with shockwave therapy. Five of those eight studies had control groups that did not receive shockwave treatment. The shockwave intervention group had significant improvements compared to the control group in all five of these studies, three of which had a level of clinical evidence $=1$. Two studies failed to show statistically significant improvements in the shockwave intervention group. However, both authors of these studies concluded that the lack of statistical significance was possibly due to small sample size. Additionally, there were multiple factors in the method of treatment administration that differed in these two studies when compared to the other eight studies, such as treatment intervals, number of shockwave impulses, age-matching in intervention vs. control group, and a lack of stated information regarding treatment protocol. Other 
more recent studies published subsequent to the current one, use the EQ-5D scale instead of the Roles and Maudsley score. This scoring system assesses five aspects of qualities of life: mobility, self-care, usual activities, self-care, anxiety/ depression. This score is utilized in Europe, yet could be considered universally in future studies $(22,24)$.

To summarize, the current study examined a cohort of patients diagnosed with Achilles tendinopathy treated with both ESWT and RSW. They received 2500 impulses of each of the two shockwave types at weekly intervals for three treatments without local anesthetic. Patients with VAS scores of 4 or more at 6 or 12 weeks post shockwave treatment were given an additional treatment or treatments. They were advised to use heel cushions during the study if they felt better with heel elevation. Patients were also advised to perform eccentric exercise, but not beyond neutral. They were required to not increase activity, and even decrease levels during the three week shockwave treatment period. In addition, they were required to avoid NSAIDs, as well as aggressive stretching. The primary endpoint was VAS and RM scores, measured at 12 weeks and $12+$ months, compared to those scores at baseline. The results showed a significant

Table II. Primary endpoint VAS scores at baseline, 1 month, 3 months, and 12+ months in shockwave intervention groups and control groups with Achilles tendinopathy.

\begin{tabular}{|c|c|c|c|c|c|c|c|c|}
\hline $\begin{array}{l}\text { Author } \\
\text { of Study }\end{array}$ & $\begin{array}{l}\text { Control } \\
\text { VAS at } \\
\text { baseline }\end{array}$ & $\begin{array}{l}\text { Shockwave } \\
\text { intervention } \\
\text { VAS at } \\
\text { baseline }\end{array}$ & $\begin{array}{l}\text { Control } \\
\text { VAS } 1 \\
\text { month post } \\
\text { treatment }\end{array}$ & $\begin{array}{l}\text { Shockwave } \\
\text { intervention } \\
\text { VAS at } 1 \\
\text { month post } \\
\text { treatment }\end{array}$ & $\begin{array}{l}\text { Control } \\
\text { VAS } 3 \\
\text { months } \\
\text { post } \\
\text { treatment }\end{array}$ & $\begin{array}{l}\text { Shockwave } \\
\text { intervention } \\
\text { VAS at } 3 \\
\text { months post } \\
\text { treatment }\end{array}$ & $\begin{array}{l}\text { Control } \\
\text { VAS } 12 \\
\text { months } \\
\text { post } \\
\text { treatment }\end{array}$ & $\begin{array}{l}\text { Shockwave } \\
\text { intervention } \\
\text { VAS at } 12+ \\
\text { months post } \\
\text { treatment }\end{array}$ \\
\hline Costa 2005 & $5.56 \pm 2.65 *$ & $5.55 \pm 3.06 *$ & $\begin{array}{l}5.03 \pm \\
3.63 * \\
\end{array}$ & $3.45 \pm 3.42 *$ & --- & --- & --- & --- \\
\hline $\begin{array}{l}\text { Current } \\
\text { Study }\end{array}$ & --- & $6.3 \pm 1.3$ & -- & --- & --- & $3.1 \pm 1.8$ & --- & $1.2 \pm 1.6$ \\
\hline
\end{tabular}

*VAS scores have been divided by 10 from those stated in Costa 2005 study

$* *$ Control group received heel-pad with 1-cm heel cushion. Shockwave (EMTT in this study) treatment group also received heel-pad with 1-cm heel cushion as adjuvant treatment

Table III. Roles and Maudsley (RM) Scores at baseline, 1 month, 3 months, and 12+ months post treatment in shockwave intervention groups and control groups with Achilles tendinopathy.

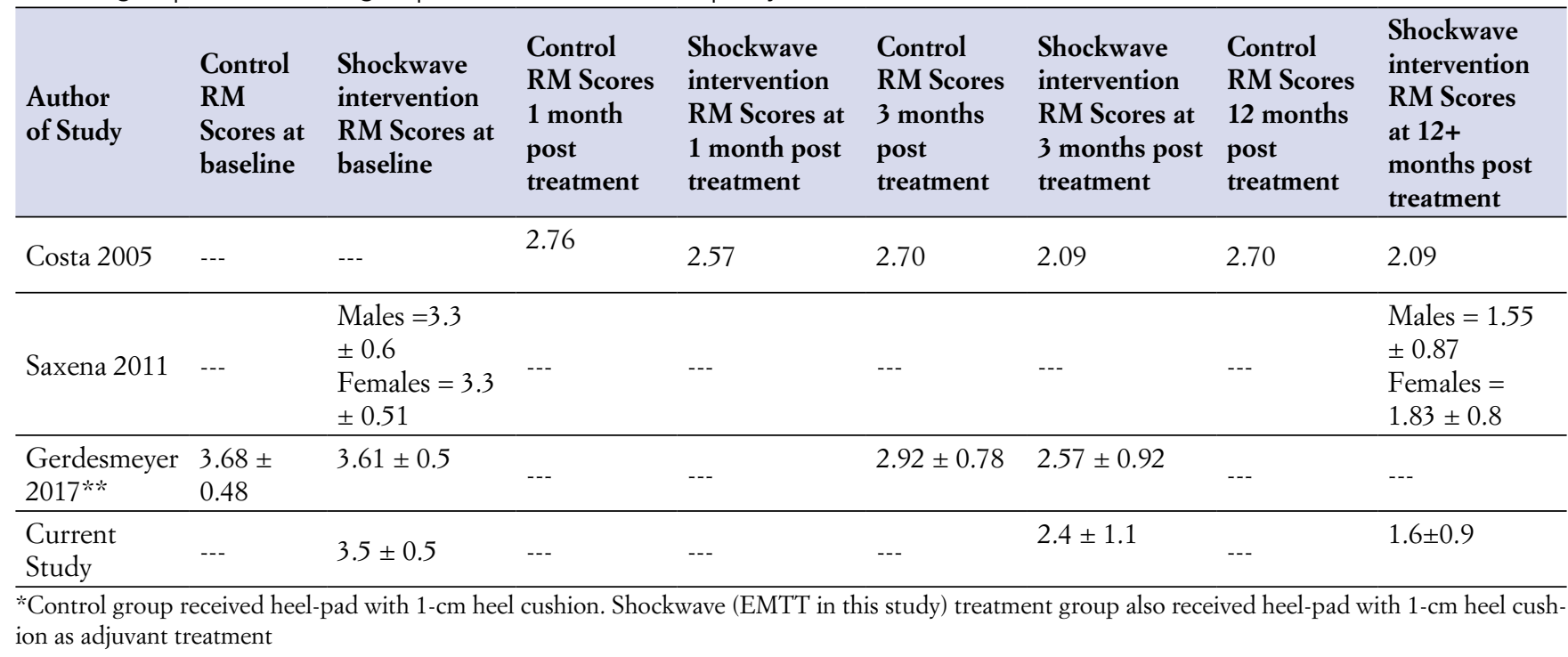


improvement in both outcome measures in patients treated with combined FSWT and RSW. Comparison of VAS and $\mathrm{RM}$ scores at baseline, one month (four weeks), three months (12 weeks), and 12+ months (all times are 'post shockwave treatment completion') for multiple studies on shockwave treatment of Achilles tendinopathy are summarized in table II (VAS scores) and table III (RM scores).

In conclusion, RSW and ESWT are both safe and effective modalities that are commonly used for treatment of Achilles tendinopathy. These injuries can be very debilitating for patients in their daily and recreational activities. We have

\section{REFERENCES}

1. Clement DB, Taunton JE, Smart GW. Achilles tendonitis and peritendinitis: etiology and treatment. Am J Sports Med. 1984;12:179-84.

2. Manias P, Stasinopoulos D. A controlled clinical pilot trial to study the effectiveness of ice as a supplement to the exercise program for the management of lateral elbow tendinopathy. $\mathrm{Br}$ J Sports Med. 2006;40:81-5.

3. Stasinopoulos D, Stasinopoulos K, Johnson MI. An exercise program for the management of lateral elbow tendinopathy. $\mathrm{Br}$ J Sports Med. 2006;40:81-5.

4. Alfredson $H$. The chronic painful Achilles and patellar tendon: research on basic biology and treatment. Scand J Med Sci Sports. 2005;15:252-9.

5. Fahlstromo M, Jonsson P, Lorentzon R, Alfredson H. Chronic Achilles tendon pain treated with eccentric calf-muscle training. Knee Surg Sports Trauma Arthrosc. 2003;327-33.

6. Ohberg L, Lorentzon R, Alfredson H. Eccentric training in patients with chronic Achilles tendinosis: normalized tendon structure and decreased thickness at follow up. Br J Sports Med. 2004;38:9-11.

7. Khan KM, Cook JL, Kannus P, Maffulli N, Bonar SF. Time to abandon the "tendinitis" myth. BMJ. 2002;324:626-7.

8. Magnan B, Bondi M, Pierantoni S, Samaila E. The pathogenesis of Achilles tendinopathy: a systematic review. Foot Ankle Surg 2014;20:154-159.

9. Joseph MF, Lillie KR, Bergeron DJ et al. Achilles tendon biomechanics in response to acute intense exercise. J Strength Cond Res 2014;28:1181-1186.

10. Wilson M, Stacy J. Shock wave therapy for Achilles tendinopathy. Curr Rev Musculoskelet Med. 2011;4:6-10.

11. Silbernagel KG1, Gustavsson A, Thomeé R, Karlsson J. Evaluation of lower leg function in patients with Achilles tendinopathy. Knee Surg Sports Traumatol Arthrosc. 2006 Nov;14(11):1207-17.

12. Gollwitzer H, Saxena A, DiDomenico LA, Galli L, Bouche RT, Caminear DS, Fullem B, Vester JC, Horn C, Banke IJ, Burgkart R, Gerdesmeyer L. Clinically relevant effectiveness of focused extracorporeal shock wave therapy in the treatment of chronic plantar fasciitis: a randomized controlled multicenter study. J Bone Joint Surg Am 2015; 97(9): 701-8.

13. Furia JP. High-energy extracorporeal shock wave therapy as a treatment for insertional Achilles tendinopathy. Am J Sports Med 2006;34:733-740. found that the use of both technologies has improved our patient outcomes and decreased or delayed the need for surgical intervention in many cases.

\section{CONFLICT OF INTERESTS}

The authors declare they have no conflict of interests.

\section{FUNDING}

Equipment and travel funding from Storz Medical for the study.
14. Rasmussen S, Christensen M, Mathiesen I, Simonson O. Shockwave therapy for chronic Achilles tendinopathy: A double-blind, randomized clinical trial of efficacy. Acta Orthop. 2008;79(2):249-56.

15. Rompe JD, Furia J, Maffuli N. Eccentric loading compared with shock wave treatment for chronic insertional achilles tendinopathy. A randomized, controlled trial. J Bone Joint Surg Am. 2008;90(1):52-61.

16. Rompe JD, Furia J, Maffuli N. Eccentric loading versus eccentric loading plus shockwave treatment for midportion achilles tendinopathy: a randomized controlled trial. Am J. Sports Med. 2009;37(3):463-70.

17. Saxena A, Ramdath S, O'Halloran P, Gerdesmeyer L, Gollwitzer H. Extra-corporeal pulsed-activated therapy ("EPAT" sound wave) for Achilles tendinopathy: a prospective study. J Foot Ankle Surg. 2011; 50(3):315-9.

18. Ziying Wu, Wei Yao, Shiyi Chen, and Yunxia Li. Outcome of Extracorporeal Shock Wave Therapy for Insertional Achilles Tendinopathy with and without Haglund's Deformity. Hindawi Publishing Corporation. Biomed Research International. Volume 2016, Article ID 6315846, 6 pages.

19. Gerdesmeyer L, Saxena A, Klueter T, Harrasser N, Fullem B, Krath A. Electromagnetic Transduction Therapy for Achilles Tendinopathy: A Preliminary Report on a New Technology. J Foot Ankle Surg. 2017; 56(5): 964-967.

20. Costa ML, Shepstone L, Donell ST, Thomas TL. Shock wave therapy for chronic Achilles tendon pain: a randomized placebo-controlled trial. Clin Orthop Related Res. 225; 440:199-204.

21. Vahdatpour B, Forouzan H, Momeni F, Ahmadi M, Taheri P. Effectiveness of extracorporeal shockwave therapy for chronic Achilles tendinopathy: A randomized clinical trial. J Res Med Sci 2018:23:37.

22. Roles NC, Maudsley RH. Radial tunnel syndrome: resistant tennis elbow as nerve entrapment. J Bone Joint Surg Br 1972: 54; 499-508.

23. Maffulli G., Padulo J., Iuliano E., Furia J, Rompe J., Maffulli N. Extracorporeal shock wave therapy in the management of midsubstance Achilles tendinopathy: the ASSERT database. Musc Lig Tend J 2018: 409-15.

24. Maffulli G., Padulo J., Iuliano E., Furia, J., Rompe J., Maffulli N Extracorporeal shock wave therapy in the management of insertional Achilles tendinopathy: the ASSERT database. Musc Lig Tend J 2018:418-22. 